
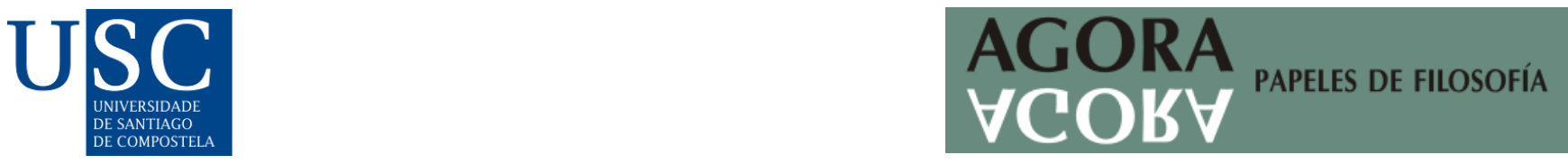

Agora. Papeles de Filosofía, 41(1), 2022. ISSN-e: 2174-3347

https://doi.org/10.15304/agora.41.1.7528

Estudios

\title{
DERECHO INTERNACIONAL Y COMUNIDAD ÉTICA EN RELIGIÓN DE KANT ${ }^{1}$
}

\author{
Noelia Eva Quiroga ${ }^{1}$ i \\ ${ }^{1}$ Universidad de Buenos Aires, Argentina
}

Recibido: 19/02/2021; Aceptado: 30/06/2021

\section{Resumen}

El objetivo de este trabajo es ofrecer una lectura en clave política de la Religión dentro de los límites de la mera razón. Para ello examinaré la manera en que el derecho internacional de Kant se aplica en el paralelo ético-jurídico en dicha obra. En primer lugar, mostraré que sin bien Kant utiliza en Religión el término "república" para referirse a la asociación de Estados, sin embargo, no sostiene el modelo de una república mundial para el derecho internacional, sino de una Federación de Estados. En segundo lugar, mostraré que Kant no sostiene una analogía estatal con el derecho internacional, sino una analogía éticojurídica entre la comunidad ética y la condición legal internacional bajo la Federación libre de Estados y el derecho cosmopolita. Por último, presentaré el sentido en que dicha analogía expone la idea de progreso que Kant tiene para las comunidades políticas existentes.

Palabras clave: Kant; derecho; ética; comunidad; mal.

\begin{abstract}
The aim of this paper is to offer a political reading of Religion within the boundaries of mere reason. For this I will examine the way in which Kant's international law is applied in the ethical-legal parallel in this work. In the first place, I will show that although Kant uses in Religion the term "republic" to refer to the association of States, however, he does not hold the model of a world republic for international law, but rather of a Federation of States. In the second place, I will show that Kant does not hold a state analogy with international law, but an ethical-legal analogy between the ethical community and the international legal condition under the free Federation of States and cosmopolitan right. Finally, I will present the sense in which this analogy exposes Kant's idea of progress for existing political communities.
\end{abstract}

Keywords: Kant; law; ethics; community; evil.

\section{INTRODUCCIÓN}

A lo largo de sus principales escritos políticos Kant introduce distintas modificaciones ${ }^{2}$ en la formulación de la teoría del derecho internacional. Esto ha llevado a que sus intérpretes discrepen 
sobre si el modelo definitivo para la institución de una condición legal internacional se trata de una república de Estados (Völkerstaat) con poder coactivo o se trata de una Federación de Estados (Völkerbund) sin poder coactivo. En este trabajo me interesa investigar el aporte que puede brindar el análisis del texto de Religión dentro de los límites de la mera razón ${ }^{3}$ (1793/94) para la reconstrucción y comprensión del paralelo ético-jurídico sostenido por Kant en el ámbito internacional.

En referencia a la formulación del derecho internacional en esta obra en particular, algunos críticos ${ }^{4}$, apoyándose en el hecho de que Kant utiliza el término "república de Estados" (RGV, VI: 34n, [53], el resaltado es mío) para referirse a la asociación a la que deberían tender los Estados, afirman que el modelo que allí se sostiene es un Estado de Estados, también llamado una república mundial. Desde dicha postura este modelo, que consiste en la institución de un poder supraestatal con el monopolio del poder coactivo, sería el único que según la razón permitiría, en analogía estatal, que los Estados abandonen el estado de naturaleza sin ley y avancen hacia un estado de paz perpetua.

Mi hipótesis es que, a partir de un análisis más de cerca de las claves políticas que Religión ofrece, puede defenderse que, si bien Kant habla de "república", sin embargo, sostiene el modelo de una Federación de Estados para el derecho internacional. Esta postura que sostengo se hace más evidente con el hecho de que, a partir del paralelo ético-jurídico que Kant presenta en Religión, puede establecerse una analogía entre la Federación y la comunidad ética, con la cual se expone el proyecto ético y cosmopolita que Kant tiene para las comunidades políticas existentes.

Para llevar adelante esta hipótesis, primeramente, expondré las claves políticas del ámbito internacional que se encuentran en Religión, a través de las cuales abordaré tanto las críticas a la monarquía universal (Universalmonarchie) como a la república mundial y defenderé la coherencia de sostener una Federación de Estados si se quiere asegurar el derecho de los pueblos y las personas. Posteriormente, mostraré la manera en que Kant rechaza una analogía estatal con el derecho internacional, y a cambio sostiene una analogía ético-jurídica entre la comunidad ética y la Federación de Estados, basada en el requisito de no coacción que tienen tanto una como la otra.

Dado que en este trabajo estudio a Religión como un texto político, complementaré mi interpretación con el análisis de las obras de la década de 1790, en las cuales Kant ha sistematizado su teoría política. Estas son Teoría y praxis (1793), Paz Perpetua (1795) y Doctrina del derecho en Metafísica de las Costumbres (1797).

\section{EL DERECHO INTERNACIONAL EN RELIGIÓN}

Si bien Kant da muy pocos datos en Religión sobre su teoría del derecho internacional, sin embargo, nos da algunas claves desde las cuales armar el rompecabezas. En lo que sigue propongo recuperar cada una de estas claves y abordar una lectura conjunta de ellas.

La primera clave se encuentra en la Primera Parte de Religión, donde Kant expone una crítica a la monarquía universal, que muestra, en principio, de qué idea de condición jurídica para el derecho internacional se separa. Una monarquía universal es definida como aquella condición jurídica en la cual los Estados individuales se disuelven para fusionarse en un Estado único bajo un jefe libre de coacción (TP, VIII: 311-312, [83-85]). Se trata de una monarquía porque hay solo una fuente de poder jurídico ${ }^{5}$, dado que se disuelven los Estados individuales y, por tanto, también su poder jurídico independiente (RGV, VI: 34n, [53]). 
En Religión Kant realiza dos críticas puntuales a la monarquía universal. La primera se basa en la descripción de la monarquía universal como resultado de un proceso en el que un Estado poderoso, al igual que un monstruo, se acrecienta devorando a los Estados vecinos, es decir, sometiendo a los Estados más débiles (Ibídem). El resultado de ello es la instauración de "una constitución en la que toda libertad y con ella (lo que es la consecuencia de la misma) toda virtud, gusto y ciencia, habrían de extinguirse" (Ibídem). Como Kant ha señalado posteriormente en Paz Perpetua, el problema de un Estado mundial único es que disuelve los poderes jurídicos individuales y, así también, la identidad de sus pueblos ( $Z e F$, VIII: 354, [256]). Al disolverse los pueblos en uno solo, cada individuo pasa a ser un ciudadano del mundo ${ }^{6}$, con lo cual desaparece la posibilidad de un derecho de los pueblos, puesto que este implica la interrelación entre pueblos de diferentes Estados (Ibídem).

La consecuencia de que un Estado único tenga un solo pueblo es que esa totalidad no puede dar cuenta de las diferencias culturales, ni pude dar soluciones frente a los conflictos que surjan en torno a las diferencias hacia su interior ${ }^{7}$. Esto contribuye a que no desaparezca el despotismo, pues al no mantenerse la diversidad de los pueblos como las fuentes de la diversidad cultural, la única forma de erradicar las diferencias es mediante la imposición de una hegemonía por parte de las reglas del más poderoso por sobre las demás.

La segunda crítica que Kant realiza a la monarquía universal descansa en que ella no erradica, sino que más bien acrecienta las guerras, las cuales son el gran azote del género humano. Kant describe este peligro de la siguiente manera:

Pero este monstruo (en el que las leyes pierden poco a poco su fuerza), después que ha devorado a todos sus vecinos, se disuelve finalmente él mismo y se divide mediante insurrecciones y discordias en muchos Estados más pequeños, los cuales, en vez de tender a una asociación de Estados (república de pueblos libres aliados), de nuevo comienzan cada uno por su parte el mismo juego, para no dejar que cese la guerra ( $R G V$, VI: 34n, [53]).

La guerra incesante devuelve a los nuevos Estados a un estado de naturaleza. De esa manera, comienza de nuevo el proceso de acrecentamiento mediante la conquista y el despotismo de los más poderosos sobre los Estados vecinos, lo cual deja cada vez más lejos el fin último de poner fin a toda guerra, es decir, de la paz perpetua.

La segunda clave, que se encuentra hacia el final de la primera sección de la Tercera Parte de Religión, consiste en una crítica a la monarquía eclesiástica en paralelo a la crítica a la monarquía universal, en los siguientes términos:

[Así como] cada Estado particular, si las cosas le van como desean, aspira a someter a los demás y a erigir una monarquía universal; pero cuando ha alcanzado una cierta magnitud se deshace por sí mismo en pequeños Estados. Así cada iglesia abriga la orgullosa pretensión de llegar a ser una iglesia universal; pero cuando se ha extendido y se hace dominante, pronto se muestra un principio de disolución y separación en diversas sectas ( $R G V$, VI: 123n, [153], traducción enmendada).

De la misma manera que Kant rechaza a nivel internacional una condición legal que lleve a una universalidad que anule las diferencias y la independencia de los pueblos, como es el caso de una monarquía universal, también rechaza a nivel eclesiástico una universalidad que signifique la dominación de una iglesia visible sobre otras más débiles. Con ello, como indica DiCenso, Kant remarca y rechaza "las tendencias hacia el imperialismo y la hegemonía por parte de las instituciones políticas y religiosas" ${ }^{8}$. 
Principalmente, esta tendencia racional a la unidad mediante la dominación de los más débiles expone, como bien señala Palmquist ${ }^{9}$, el problema de la exigencia de universalidad para las iglesias visibles tal como aparecen en la historia real. Una monarquía universal solo llevaría a una unidad que tiende a romperse en su interior y que es foco de nuevas conflictividades traducidas en guerras de religión, que en la historia no han sido otra cosa que derramamientos de sangre por disputas sobre creencias eclesiásticas ( $R G V, \mathrm{VI}$ : 108, [135]). De hecho, en Religión Kant menciona que la diversidad de religiones junto a la diferencia de idiomas son las causas que impiden la tendencia natural de los Estados a unirse en federaciones más grandes (RGV, VI: 123n, [153]). En cuanto a ello en Paz Perpetua dice:

Estas diferencias encierran siempre en su seno un germen de odio y un pretexto de guerras; pero con el aumento de la cultura y la paulatina aproximación de los seres humanos a un mayor acuerdo en los principios, estas diferencias conducen a concertar la paz [...] (ZeF, VIII: 367, [267], traducción enmendada).

La solución que brinda Kant al problema de la universalidad en Religión consiste en que las iglesias visibles deben intentar acercarse lo más posible al arquetipo de la iglesia invisible, es decir, a una comunidad ética (RGV, VI: 100, [126]). Las disputas sobre los principios de virtud solo son superadas con la erección de una comunidad ética, la cual consiste en la unidad de los individuos bajo leyes éticas públicas que expresan los conceptos morales universales de la única religión, a saber, la religión moral. Mediante el logro de esta comunidad religiosa es posible alcanzar la paz eterna (ewigen Frieden) en este mundo terrenal (RGV, VI: 124, [153]). La verdadera universalidad está en la expresión de la religión moral, que contiene la diversidad en su interior en tanto existe una única religión pero múltiples modos de creencias (RGV, VI: 107, [134]). Puede haber una división en muchas iglesias visibles ${ }^{10}$, diversas formas de creencia, pero todas ellas son una manifestación de la única y misma religión, la moral (Ibídem).

La tercera clave se encuentra en el pasaje arriba citado de la Primera Parte de Religión, donde Kant habla de que mediante una asociación de Estados, de pueblos libres (RGV, VI: 34n, [53]) se pondría fin a las guerras entre los Estados. Más adelante en Paz Perpetua lo dice así: si se quiere un derecho internacional sin violar el derecho de gentes,

entonces, para no perderlo todo en lugar de la idea positiva de una república universal, puede acudirse al recurso negativo de una federación de pueblos que, mantenida y extendida sin cesar, evite las guerras y ponga un freno a las tendencias perversas e injustas [...] (ZeF, VIII: 357, [259]).

Para dar un sentido correcto a este pasaje debe leerse junto al pasaje que constituye la cuarta clave, que se encuentra en la Tercera Parte de Religión, donde Kant dice que los Estados políticos diversos que no están en ninguna ligazón mediante un público derecho de gentes se hallan en un estado de naturaleza entre sí (RGV, VI: 96, [121]). Esto significa que los Estados se encuentran permanentemente expuestos a intromisiones por parte de las potencias extranjeras en sus asuntos domésticos, lo cual pone en riesgo la protección y mantención de sus propias constituciones y gobiernos. Para salir de dicho estado de naturaleza es necesario establecer un derecho internacional, es decir, un pacto entre los Estados para protegerse mutuamente de los ataques de los enemigos externos y alcanzar un verdadero estado de paz ${ }^{11}$ (MS, VI: 344, [182]; 350, [190]).

Kant habla en Religión de una asociación internacional, no en la forma de un Estado mundial ${ }^{12}$, sino de una Federación de Estados libres e independientes, que es la única forma en la que debe fundarse el derecho de gentes (ZeF, VIII: 354, [256]; MS, VI: 351, [191]). 
De hecho, Kant no podría estar hablando de un Estado mundial por dos razones. Primero y principal, los Estados que se encuentran en interacciones inevitables entre sí, para afirmar su seguridad tienen que formar una condición legal que asegure el derecho de cada uno. Pero dicha asociación, como Kant reafirma en Paz Perpetua, no puede ser una república de Estados, porque ello implicaría una contradicción:

Todo Estado implica la relación de un superior -el que legisla- con un inferior -el que obedece, el pueblo-; muchos pueblos, reunidos en un Estado, vendrían a ser un solo pueblo, lo cual contradice la hipótesis; en efecto, hemos de considerar aquí el derecho de los pueblos, unos respecto de otros, precisamente en cuanto que forman diferentes Estados y no deben fundirse en uno solo (ZeF, VIII: 354, [256]).

El derecho internacional, que consiste en la condición legal que permite regular las acciones entre Estados, tiene como requisito primero que los Estados se mantengan independientes, es decir, que se respete la soberanía estatal ${ }^{13}$. En Paz Perpetua Kant dice que ningún Estado puede obligar a otro a entrar en una constitución legal porque son todos independientes y jurídicamente iguales en cuanto que cada uno ya posee su propia constitución jurídica interna (ZeF, VIII: 355, [257]). Si sucediera que un Estado se incorporara a otro, como sería el caso de la conformación de un Estado mundial, su persona moral y su independencia jurídica quedarían anuladas (ZeF, VIII: 344, [247]). En otras palabras, "ningún Estado debe inmiscuirse por la fuerza en la constitución y el gobierno de otro Estado" (ZeF, VIII: 346, [249]), dado que toda interferencia por la fuerza implica siempre una violación de los derechos de un pueblo libre e independiente, poniendo en riesgo la autonomía de todos los Estados (ibídem).

La autonomía y soberanía de los Estados solo puede asegurarse en una condición legal bajo una Federación no coercitiva, en la cual se respete tanto la constitución jurídica interna de cada Estado como los derechos de sus pueblos y de las personas que los conforman. Así pues, como Kant afirma, sin esta idea de Federación, el concepto del derecho de gentes carecería de todo contenido pensable (ZeF, VIII: 356, [258]).

La segunda razón contundente contra al modelo de república de Estados se encuentra en Metafísica de las Costumbres. La crítica consiste en que una república de Estados no puede llevar a cabo un gobierno perfecto y, con ello, tampoco la protección de cada miembro. La consecuencia de la falta de gobierno conduciría a que algunos de los Estados vuelvan a encontrarse entre sí en un estado de naturaleza, es decir, en un estado de guerra. Esto haría imposible cumplir con la paz perpetua, que es el fin último del derecho de gentes en su totalidad (MS, VI: 350, [190]).

Teniendo en cuenta estas razones, considero que el modelo del derecho internacional que Kant sostiene desde Religión cuando habla de asociación de Estados no es el de una república de Estados, sino el de una Federación o Liga voluntaria de Estados no coercitiva, cuya función, como dice en Paz Perpetua, es mantener y asegurar la libertad de todos los Estados federados, sin que ellos deban someterse a un poder supranacional con poderes $\operatorname{coactivos}^{14}$ (ZeF, VIII: 356, [258]). Se trata de una alianza a la que puede unirse cualquier vecino y que puede disolverse y renovarse a lo largo del tiempo (MS, VI: 344, [182-183]; 350, [191]). Solo mediante esta Federación es posible contrarrestar todas las guerras presentes o futuras ( $Z e F$, VIII: 356, [258]), es decir, es posible todo tratado de paz necesario para avanzar hacia una paz perpetua.

El derecho internacional para Kant consiste en la posibilidad de que cada Estado se constituya en una república, y que cada república, conforme a la idea del derecho de gentes, se incorpore voluntariamente a una Federación, la cual se irá extendiendo poco a poco hasta comprender en sí a todos los Estados. Kant dice que la posibilidad de llevar a cabo esta idea de Federación, que 
conducirá a los pueblos a la paz perpetua, "es susceptible de exposición y desarrollo" (ZeF, VIII: 356, [257]).

Este desarrollo del cual habla, no refiere a que la Federación sea un eslabón medio en un camino indirecto hacia una república de $\operatorname{Estados}^{15}$, sino que la forma final del derecho internacional es la Federación, porque solo mediante ella es posible la conformación de un derecho internacional sin socavar el derecho de gentes. En Metafísica de las Costumbres Kant lo dice claramente así:

Sólo por la mediación de tal congreso [de Estados] puede realizarse la idea de un derecho público de gentes -que es menester establecer-para resolver los conflictos de un modo civil, digamos por un proceso y no de una forma bárbara (como los salvajes), es decir, mediante la guerra (MS, VI: 351, [191], traducción enmendada).

Aproximarnos a la idea de un derecho público de gentes es una tarea y un deber, por tanto, también un derecho de los individuos y de los Estados (MS, VI: 350, [191]).

Así, a partir de una lectura conjunta de las claves presentadas sobre el derecho internacional, podemos decir que el único modelo admisible para Kant es el de una Federación de Estados. Si habla en términos de república de pueblos ( $R G V$, VI: 34n, [53]), solo puede estar refiriéndose, como bien señala Marey ${ }^{16}$, a un "giro" para designar la unidad de todos los Estados en una Federación mundial que tiene las características de una liga libre no coercitiva y de unidad progresiva.

\section{EL PARALELO ÉTICO-JURÍDICO EN EL ÁMBITO INTERNACIONAL}

Los comentarios de Kant sobre el derecho internacional adquieren un nuevo prisma cuando se analiza el paralelo ético-jurídico que expone en la Tercera Parte de Religión. Entiendo este paralelo en los siguientes términos: así como los Estados deben salir del estado de naturaleza y establecer una condición jurídica entre sí, según la cual cada Estado se adhiera voluntariamente a una Federación con los demás Estados libres, a fin que esta asociación se vaya extendiendo hasta abarcar a todos los Estados (ZeF, VIII: 356, [257]; MS, VI: 344, [182], 350, [190]); así también, los ciudadanos de las comunidades políticas existentes deben abandonar el estado de naturaleza ético y conformar de forma plenamente libre una comunidad ética bajo leyes comunes públicas de virtud (RGV, VI: 94-96, [118-120]).

En lo que sigue quisiera mostrar la manera en que Kant rechaza una analogía estatal con el derecho internacional y, a cambio, sostiene una analogía ético-jurídica entre la comunidad ética y la condición legal internacional bajo la Federación libre de Estados y el derecho cosmopolita.

Comencemos por analizar el estado de naturaleza entre Estados. Kant dice que, al igual que sucede entre los individuos, ya sea a nivel ético o jurídico, los Estados se hallan en estado de naturaleza uno frente al otro cuando no hay un poder común y cada uno es juez de su propia causa (RGV, 96-97, [121-122]; ZeF, VIII: 354-355, [256-257]; MS, VI: 344, [182]).

Desde el punto de vista jurídico existe una diferencia entre los individuos y los Estados en el estado de naturaleza, pues mientras que los individuos no poseen ley jurídica alguna, los Estados ya poseen sus constituciones internas, y por tanto, cada uno ya es un Estado de derecho que se guía por sus propias leyes coactivas y es una persona moral frente a los otros Estados.

Sin embargo, al igual que sucede sin una condición civil entre los individuos, si los Estados no establecen entre sí una condición legal que regule las relaciones externas, se hallan así en un constante estado de guerra, ya sea efectiva o latente (RGV,VI: 94, [118]; (MS, VI: 343, [181]). Aunque 
no haya una hostilidad activa, el solo hecho de hallarse en un estado de naturaleza (ya sea para los individuos o para los Estados) lesiona a la libertad de los demás, pues sin una condición legal se está siempre en posibilidad latente de que los acuerdos de no dañar a otro Estado se derrumben y se caiga nuevamente en guerra (RGV, VI: 34, [53]; ZeF, VIII: 346-347, [250]; 348-349, [252]; MS, VI: 346 [185]). La amenaza se produce porque el estado de naturaleza de los pueblos, al igual que el de los individuos, es un estado en que "el derecho de los pueblos y todo lo mío y tuyo externo de los Estados, que se adquiere y conserva mediante la guerra, es únicamente provisional” (MS, VI: 350, [190]).

Paralelamente a este punto de vista jurídico, según el cual los Estados sin establecer una condición legal entre sí se encuentran en estado de naturaleza jurídico, Kant plantea, desde el punto de vista ético, que los ciudadanos sin leyes públicas de virtud se hallan en un estado de naturaleza ético (RGV, VI: 96, [120]). Dicho estado también se caracteriza por no tener una autoridad pública común y por ser cada uno juez de su propiacausa. La consecuencia de ello para los individuos es un público hacerse la guerra mutuamente a los principios de virtud y un estado de interna amoralidad (RGV, VI: 97, [122]).

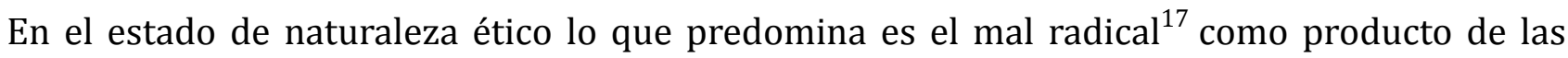
elecciones libres del arbitrio en un marco que lo propicia: un contexto social que promueven las acciones basadas en el amor propio ${ }^{18}$ (egoísmo). Kant da cuenta de que los seres humanos no somos agentes morales aislados, sino que nuestra libertad opera en su contexto histórico social, el cual influye en la manera que interpretamos las situaciones y que elegimos nuestros incentivos para actuar. Es en cuanto los seres humanos estamos en contacto unos con otros que se activan nuestras inclinaciones hostiles y nos corrompemos mutuamente en nuestra disposición moral, de forma que nos hacemos malos unos a otros (RGV, VI: 94, [118]). En la sociabilidad, las comparaciones, la búsqueda del reconocimiento por parte de los otros y el intento de dominación sobre los demás, dan lugar a los llamados vicios de la cultura, como ser la codicia, el ansia de poder, la ingratitud y la alegría por el mal ajeno (RGV, VI: 27, [44-45]).

Ahora bien, siguiendo el paralelismo, existe un deber de abandonar los estados de naturaleza. Así como los Estados que se encuentran en relaciones externas inevitables deben abandonar el estado de naturaleza en el que se hallan uno frente al otro y pasar a un estado legal (TP, VIII: 312, [86]; ZeF, VIII: 354, [256]; MS, VI: 344, [182]; 350, [190]), de la misma manera debe abandonarse tan pronto como se pueda el estado de naturaleza ético en el que se hallan los individuos en medio de una comunidad política sin leyes de virtud y pasar a conformar una comunidad ética (RGV, VI: 96-97, [120-122]).

Si analizamos más de cerca al exeundum en el plano jurídico internacional, encontramos que Kant sostiene una desanalogía estatal, pues a diferencia de los individuos, que pueden ser obligados a abandonar el estado de naturaleza para entrar junto a los otros en un estado jurídico civil (ZeF, VIII: 349, [252]; MS, VI: 264, [81]), los Estados, si bien tienen el deber de salir del estado de naturaleza, no pueden ser coaccionados a ello ${ }^{19}$, sino que deben ingresar libremente a una Federación con otros Estados libres (ZeF, VIII: 355, [257]; MS, VI: 344, [182]). La razón por la cual no pueden ser coaccionados radica en que cada Estado ya posee una constitución jurídica interna, es decir, ya posee una persona moral y jurídica. Si un Estado fuera coaccionado, se estaría avasallando su autonomía, pues quedaría reducido a una constitución común impuesta bajo los conceptos del derecho de otro Estado en desmedro de los propios (ZeF, VIII: 355, [257]). 
Esta restricción que tienen los Estados para ser coaccionados a ingresar en una condición legal tiene un paralelo con el exeundum ético ${ }^{20}$. Así como los Estados deben entrar en una Federación voluntaria de Estados, del mismo modo los individuos en estado de naturaleza ético deben ingresar libremente en una comunidad ética. El exeundum ético tampoco puede ser mediante coacción porque ello sería una contradicción dado que la comunidad ética "ya en su concepto lleva consigo la libertad respecto a toda coacción" (RGV, VI: 95, [120] $)^{21}$. Los ciudadanos de una comunidad política pueden decidir si ingresan también a una comunidad ética y ello debe ser absolutamente de forma voluntaria, por eso se trata de un deber sui generis.

Si ahora vemos más de cerca al exeundum ético, ante todo debemos entender lo siguiente: que los individuos aun viviendo en una comunidad política pueden hallarse en un estado de naturaleza ético de acuerdo a sus disposiciones internas para el mal. Pues, si bien el mal es un producto social, porque nuestras elecciones morales se dan en contextos sociales e históricos y nuestras acciones tienen consecuencias en el mundo terrenal en el que vivimos, no por ello un poder externo es suficiente para terminar con el mal. En este sentido, la posición de Kleingeld resulta incompleta cuando dice que:

el hecho de que los seres humanos son libres, relacionado con la propensión hacia el mal que está enraizada en la naturaleza humana, significa que ellos en principio plantean una amenaza a la libertad externa de unos y otros, y esta amenaza necesita ser contrarrestada con un sistema de leyes públicas y coercitivas ${ }^{22}$.

Es incompleta porque el mal social que caracteriza el estado de naturaleza ético solo puede ser contrarrestado de forma definitiva con la entrada a una comunidad ética (RGV, VI: 93-95, [117-118]). Es decir, no con leyes externas y coercitivas, sino con leyes puramente internas y no coactivas.

Pero que sean internas no significa que el orden ético sea invisible en oposición a un orden político visible, como afirma Flikschuh ${ }^{23}$, sino que en Religión Kant plantea un orden ético establecido por la erección de una comunidad ética sobre la Tierra, en la cual todas las leyes éticas están propiamente ordenadas a promover la moralidad de las acciones (que es algo interior) y, con ello, a contrarrestar el mal. Si bien provienen de una legislación puramente interior (no coactiva) ( $R G V$, VI: 98, [123]), se tratan de leyes éticas que son públicas (RGV, VI: 99, [124]). Por consiguiente, el ámbito público contiene tanto a las comunidades políticas, con leyes públicas externas para las libertades externas, como a la posibilidad de erigir una comunidad ética desde ellas, con leyes públicas internas para las libertades internas.

Ahora puede verse más claramente la siguiente cuestión: el mal traducido en guerras activas o latentes tiene para Kant una doble solución en la esfera pública, a saber, una en el ámbito jurídico y otra en el ámbito ético-político.

Desde el punto de vista jurídico, se requiere la realización del derecho público en sus tres formas. Primero, el mal traducido en guerras como producto de la falta de legalidad en el estado de naturaleza jurídico obliga a los individuos a formar un Estado. Luego, el derecho internacional debe proporcionar una condición legal bajo la forma de una Federación para regular las relaciones internacionales y evitar las guerras, respetando a sus constituciones internas, al derecho de los pueblos y de las personas. Se trata de una asociación, de un derecho in subsidium de otro originario, que consiste en defenderse de posibles ataques externos o internos (MS, VI: 344, [183]), y que debe extenderse a todos los pueblos de la Tierra. 
Con vistas a proporcionar el conjunto de leyes necesarias para producir una condición jurídica y alcanzar la paz duradera, en Paz Perpetua y en Metafísica de las Costumbres, Kant da cuenta de que el derecho público requiere, además del derecho político y del derecho internacional, un derecho cosmopolita (ZeF, VIII: 349 n., [252]; $M S$, VI: 311, [140]). No se puede separar un derecho del otro, sino que se trata de tres formas del derecho interdependientes para conformar una condición legítima y lograr la idea de la paz perpetua. De modo que,

con tal de que a una de estas tres formas de estado jurídico le falte el principio que restringe la libertad externa mediante leyes, el edificio de las restantes queda inevitablemente socavado y acaba por derrumbarse (MS, VI: 311, [140]).

El derecho público implica una regulación de las relaciones externas tanto entre individuos de un mismo Estado, como entre los Estados, como entre un individuo y los demás Estados y los individuos que los conforman (MS, VI: 344, [182]). Considerando esta coyuntura, la asociación pacífica de todos los pueblos requiere que se garantice tanto el derecho de las personas a ser respetadas en su humanidad en cualquier parte del mundo, como también el derecho de los Estados a que se respete su soberanía o la no intervención en la constitución y en el gobierno de cada uno de ellos ${ }^{24}$.

Dada la posesión común de la Tierra y que la Tierra es una esfera limitada (por lo cual no se puede evitar la interacción mutua), se hace necesario instituir un derecho cosmopolita que permita establecer una relación universal pacífica entre todos los pueblos de la Tierra, es decir, entre las personas de todos los Estados ${ }^{25}$. Se trata del derecho a la hospitalidad, que consiste en prestarse a una interacción ${ }^{26}$ pacífica y a no ser tratado como un enemigo en territorio extranjero (ZeF, VIII: 357-360, [259-261]; MS, VI: 352, [192]). No es el derecho a exigir el trato de un huésped (de hecho, ingresar y permanecer en territorio extranjero requiere un permiso), sino que es simplemente el derecho a presentarse en una sociedad ( $Z e F$, VIII: 358, [259]).

Sin este derecho, como dice O’Neill, las medidas para asegurar la paz no serían más que provisorias, no tendríamos ningún derecho seguro ${ }^{27}$. El derecho cosmopolita complementa al derecho internacional porque asegura la comunicación y el intercambio pacífico entre los Estados soberanos y entre quienes conforman sus pueblos. Principalmente asegura la no intrusión imperialista $^{28}$ de los Estados más poderosos sobre los más débiles y asegura el derecho de las personas independientemente del Estado del cual provengan y del territorio en el que se encuentran.

La conclusión de Kant es que mediante el derecho cosmopolita "las comarcas lejanas pueden entrar en pacíficas relaciones entre sí, las cuales si se convierten en públicas y legales, finalmente podrían acercar a la especie humana a una constitución cosmopolita" (ZeF, VIII: 358, [260], traducción enmendada). Esta constitución cosmopolita requiere, como indica Anderson-Gold ${ }^{29}$, que la Federación de Estados no sea un "sistema cerrado", dado que para garantizar la interacción pacífica entre los Estados y evitar futuras guerras con los Estados aislados, el derecho internacional y el derecho cosmopolita tienen que abarcar a todos los Estados del mundo, a fin de que sus relaciones estén reguladas por leyes públicas y normas cosmopolitas de hospitalidad (MS, VI: 352, [192]).

Ahora bien, puesto que el cumplimiento del derecho refiere solo a la coexistencia de las libertades externas, ya sea de los individuos como de los Estados, y que el derecho internacional puede ser llevado a cabo por un "pueblo de demonios" (ZeF, VIII: 336, [266]), quedan aún latentes 
las tendencias al mal que se corresponden con nuestras disposiciones morales y que no pueden ser coaccionadas. Al derecho solo le corresponde la legalidad de las acciones y no la moralidad, que es algo interior ( $R G V, \mathrm{VI}$ : 99, [124]). Por ello, si se quiere alcanzar el triunfo definitivo del principio bueno sobre el malo en la Tierra y lograr una paz duradera, los seres humanos en su conjunto deben llevar a cabo también una comunidad ética sobre la Tierra (RGV, VI: 93, [117]).

Esta comunidad es el principio que unifica a todos los seres humanos bajo las leyes públicas de virtud y en dirección a un fin comunitario, a saber, el bien supremo comunitario ${ }^{30}(R G V$, VI: 97, [122]). Kant dice:

puesto que los deberes de virtud conciernen a toda la especie humana, el concepto de una comunidad ética está siempre referido al ideal de una totalidad de los seres humanos, y en ello se distingue del de una comunidad política ( $R G V$, VI: 96, [121], traducción enmendada).

El alcance de la comunidad ética tiene que ser universal, tiene que ser un todo ético absoluto, del cual toda sociedad parcial es solo una representación o un esquema. No obstante, la universalidad que requiere la comunidad ética no debe confundirse con la universalidad que se espera en el derecho cosmopolita, dado que esta idea racional de una comunidad pacífica universal formada por una Federación de todos los pueblos de la Tierra que pueden establecer relaciones externas efectivas entre sí, es un principio jurídico y no ético (MS, VI: 352, [192]).

Si bien son dos principios diferentes, tanto la idea de una constitución cosmopolita como la idea de una comunidad ética son para Kant ideas regulativas, cuya aproximación es considerada una tarea fundada en el deber, en el caso jurídico, en un deber jurídico y un derecho de los individuos y los Estados (MS, VI: 350, [190-191], mientras que en el caso ético, en un deber ético para modificar a las sociedades éticas parciales y realizar el bien supremo comunitario $(R G V, 6: 98,[123])$. Ambas ideas son necesarias según la razón para poner fin a las guerras y alcanzar la paz duradera en la Tierra.

\section{CONCLUSIÓN}

En este trabajo he sostenido que la obra de Religión es una pieza que al encastrarla en el corpus político kantiano permite comprender su proyecto cosmopolita y, a la vez, ético para las comunidades políticas existentes.

Religión ofrece claves fundamentales para exponer el modelo definitivo que Kant elige para la asociación entre Estados. Dicho modelo, como vimos, no puede ser el de una república mundial, porque si así fuere haría incoherente a la postura kantiana de que el derecho internacional no puede socavar el derecho de los pueblos, esto es, a su soberanía e independencia, ni el derecho de las personas que integran esos pueblos, en lo que respecta al uso externo de su libertad y al respeto de su humanidad. El único modelo que evita esta contradicción es el de una Federación voluntaria de Estados libres, el cual, además, hace de base para una condición cosmopolita que posibilite una asociación pacífica universal requerida por el derecho público.

Llegado a este punto, Religión revela, a su vez, el sentido en que la analogía ético- jurídica expone la idea de progreso para las comunidades políticas existentes. Ante todo el paralelismo muestra que el punto de partida para lograr el progreso desde lo peor a lo mejor es el mal. El mal, tanto desde el punto de vista ético como desde el punto de vista jurídico, se traduce en guerras producto de 
la interacción inevitable entre los seres humanos y entre los Estados, cuando esta interacción se desarrolla sin leyes públicas comunes, ya sean jurídicas como éticas.

En la "garantía" de Paz Perpetua Kant nos dice que la Naturaleza se sirve de las guerras para avanzar hacia la paz perpetua y que ello depende, no de la mejora moral del ser humano, sino de un mecanismo de la Naturaleza,

y el problema es averiguar cómo se ha de utilizar ese mecanismo natural en el ser humano, para disponer las contrarias y hostiles inclinaciones de tal manera que todos los individuos se sientan obligados por fuerza a someterse a las leyes y tengan que vivir por fuerza en pacíficas relaciones, obedeciendo a las leyes $(\mathrm{ZeF}$, VIII: 366, [266]).

Pero mientras en Paz Perpetua Kant aborda el progreso solo desde una cara, la jurídica, en Religión lo aborda tanto desde la cara jurídica como desde la ética, lo cual nos permite ver con mayor claridad la solución integral que brinda para el mal.

La naturaleza nos asegura el progreso desde lo peor a lo mejor, pero las acciones que tomamos partiendo de los males incrustados en nuestra naturaleza dependen de nosotros, y no de un obrar aislado e individual, sino de nuestro obrar conjunto. Salir del estado de naturaleza jurídico como del ético es un deber moral para todos los seres humanos, aunque no sepamos si está en nuestro poder lograrlo. En el planteo de Kant en Religión la superación del mal y la búsqueda del logro de la paz perpetua, la cual implica poner fin a todas las guerras, esto es, no solo las que se dan en las relaciones externas sino también las que se dan entre las disposiciones internas, requieren la interrelación de los dominios ético y jurídico. Pues, el derecho internacional y cosmopolita es insuficiente para lograr el fin de la paz. Es insuficiente porque sin establecer una condición ética, el mal subsiste en las disposiciones a hacer guerra. Podemos obedecer a las leyes jurídicas y seguir siendo un pueblo de demonios. Sin embargo, no por ser insuficiente deja de ser necesario, pues el derecho aborda una cara del progreso moral. Sin el establecimiento de las comunidades políticas los individuos no pueden salir del estado de guerra que representa el estado de naturaleza jurídico, en el cual no se puede asegurar a cada uno lo suyo. Sin una Federación de Estados, los Estados no pueden proteger sus constituciones y sus pueblos. Y sin un derecho cosmopolita no puede lograrse el intercambio pacífico entre todos los Estados independientes y soberanos, y por tanto, no puede lograrse el ideal de una Federación libre que abarque a todos los pueblos de la Tierra para alcanzar la paz perpetua.

Para ponerlo en otras palabras, el derecho solo puede dirigirse hacia la realización del bien supremo político, que no es ético sino jurídico, pues refiere al término de toda guerra presente y futura respecto de las relaciones externas entre los Estados y los individuos que los conforman. Queda así vacante una solución para las disposiciones internas a las guerras. En consecuencia, Kant plantea frente a ello que debemos pasar, en un segundo lugar y sobre esta base sociopolítica, a un ideal ético para lograr establecer relaciones comunitarias que tengan fines éticos comunes. Las relaciones éticas internas entre los individuos, las cuales no pueden ser coaccionadas, deben ser abordadas por otro lado, a través de la comunidad ética, bajo leyes éticas públicas. El todo ético debe abarcar a todas las sociedades éticas parciales, o dicho de otro modo, a todas las comunidades políticas existentes que se encuentran en estado de naturaleza ético. Solo así podrá sostenerse un estado de paz duradero, que es el triunfo del bien sobre la Tierra. Ello Kant lo expresa en Religión del siguiente modo:

[la unión de los ánimos en orden al bien] es, pues, un trabajo [...] del principio bueno en orden a erigirse en el género humano, en cuanto comunidad según leyes de virtud, un poder y un reino, lo cual afirma el triunfo sobre el mal y asegura al mundo, bajo el dominio del principio bueno, una paz eterna ( $R G V$, VI: 124, [153]). 
Kant considera que, si bien esta tarea que tenemos los seres humanos no está consumada, aun con las luchas que quedan contra los males que azotan a la humanidad, nos dirigimos hacia su constante progreso. En Teoría y Praxis concluye:

Puesto que el género humano está, desde el punto de vista de la cultura, que es su fin natural, en progreso constante, ha de ser concebido también en progreso hacia lo mejor desde el punto de vista del fin moral de su existencia, progreso que ciertamente puede resultar a veces interrumpido pero jamás roto (TP, VIII: 308-309, [79]).

\section{Bibliografía}

Anderson-Gold, S., “Cosmopolitan Right: State and System in Kant's Political Theory”, in Baiasu S., Pihlström S. and Williams H. (Eds.), Politics and Metaphysics in Kant, Cardif, University of Wales Press, 2011, pp. 235-249.

Beade, I., "Acerca de la relación entre derecho político, derecho de gentes y derecho cosmopolita en la filosofía kantiana del derecho", Las Torres de Lucca. Revista Internacional de Filosofía Política, Vol.7, № 13, 2018, pp. 81-108.

Byrd, S. / Hruschka, J., Kant's Doctrine of Right. A Commentary, Cambridge, Cambridge University Press, 2010.

DiCenso, J., Kant's Religion within the Boundaries of Mere Reason: A Commentary, Cambridge, Cambridge University Press, 2012.

Cavallar, G., Kant and the Theory and Practice of International Right, Cardiff, University of Wales Press, 2020.

Flikschuh, K., Kant and modern political philosophy, Cambridge, Cambridge University Press, 2000.

Flikschuh, K., "Kant's sovereignty dilemma: A contemporary analysis”, Journal of Political Philosophy, 18, 2010, pp. 469-493.

Kant, I., (MS) Die Metaphysik der Sitten, en Gesammelte Schriften, tomo VI, pp. 205-493. [Metafísica de las Costumbres, Trad. Cortina Orts A. y Conill Sancho J., Barcelona, Altaya, 1996].

Kant, I., (RGV) Die Religion innerhalb der Grenzen der bloßen Vernunft, en Gesammelte Schriften, tomo VI, pp. 1-102. [Religión dentro de los límites de la mera Razón, Trad. Martínez Marzoa F., Madrid, Alianza, 2007].

Kant, I., (TP) Über den Gemeinspruch: Das mag in der Theorie richtig sein, taugt aber nichts für die Praxis, en Gesammelte Schriften, tomo VIII, pp. 273-314. [Teoría y Praxis, Trad. Correa C., Buenos Aires, Leviatán, 1984].

Kant, I., (ZeF) Zum ewigen Frieden, en Gesammelte Schriften, tomo VIII, pp. 341-386. [La Paz Perpetua, Trad. Larroyo F., D.F., Porrúa, 2007].

Kleingeld, P., “Approaching Perpetual Peace: Kant's Defence of a League of States and his Ideal of a World Federation", European Journal of Philosophy, 12(3), 2004, pp. 304-325.

Kleingeld, P., "Kant's changing cosmopolitanism”, in Oksenberg Rorty A. and Schmidt J. (Eds.), Kant's Idea for a Universal History with a Cosmopolitan Aim, New York, Cambridge University Press, 2009, pp. 171-186.

Kleingeld, P., Kant and cosmopolitanism: The Philosophical Ideal of World Citizenship, Cambridge, Cambridge University Press, 2012.

Marey, M., El derecho en Kant: Una investigación de sus fundamentos [en línea], Universidad Nacional de La Plata, Facultad de Humanidades y Ciencias de la Educación, 2010. http://www.memoria.fahce.unlp.e du.ar/tesis/te.351/te.351.pdf

Marey, M., "Kant's popular sovereignty and cosmopolitanism”, Constellations. An International Journal of Critical and Democratic Theory, 2020, pp. 361-374. 
O'Neill, O., Constructing authorities: Reason, politics and interpretation in Kant's philosophy, Cambridge, Cambridge University Press, 2015.

Papish, L., Kant on evil, Self-Deception, and Moral Reform, New York, Oxford University Press, 2018.

Palmquist, S., Comprehensive Commentary on Kant's Religion within the Bounds of Bare Reason, United Kingdom, Wiley Blackwell, 2016.

Quiroga, N., "El origen, objetivo y función de la comunidad ética en La religión dentro de los límites de la mera razón de Kant", Anales del Seminario de Historia de la Filosofía, 37(3), 2020, pp. 437-447.

Rossi, P., The social Authority of Reason: Kant's critique, Radical Evil, and the Destiny of Humankind, Albany, State University of New York Press, 2005.

Williams, H., "Kantian Cosmopolitan Right", Politics and Ethics Review, 3(1), 2007, pp. 57-72.

Wood, A., Kant's Ethical thought, Cambridge University Press, Cambridge, 1999.

Notas

$1 \quad$ Agradezco a Macarena Marey por acompañar mi trabajo con sus consejos y observaciones.

2 Acerca de los cambios en la teoría del derecho internacional y cosmopolita en los escritos políticos de Kant pueden consultarse los diferentes análisis de: P. Kleingeld, "Kant's changing cosmopolitanism", in Oksenberg Rorty A. and Schmidt J. (Eds.), Kant's Idea for a Universal History with a Cosmopolitan Aim, New York, Cambridge University Press, 2009, pp. 179-185; S. Byrd / J. Hruschka, Kant's Doctrine of Right. A Commentary, Cambridge, Cambridge University Press, 2010, pp. 196-211; G. Cavallar, Kant and the Theory and Practice of International Right, Cardiff, University of Wales Press, 2020, pp. 141-160.

3 En adelante me referiré a esta obra de forma abreviada como Religión. Siguiendo el uso establecido, en este trabajo las referencias a las obras de Kant se citan primero por medio de la sigla de la obra correspondiente seguidos por el volumen y la página de Kants gesammelte Schriften (Academia Alemana de Ciencias, Berlín) seguidos, entre corchetes, por la página en las traducciones castellanas indicadas en las referencias bibliográficas. Asimismo se indicará al final de la referencia cuando la traducción haya sido enmendada.

4 Cf. S. Byrd/ J. Hruschka, Kant's Doctrine of Right. A Commentary, op. cit., p. 199; J. DiCenso, Kant's Religion within the Boundaries of Mere Reason: A Commentary, Cambridge, Cambridge University Press, 2012, p. 177.

5 En Teoría y Praxis Kant lo define como "una comunidad cosmopolita bajo un jefe" (TP, VIII: 311, [83]).

6 En Paz Perpetua y en Doctrina del Derecho Kant da otra significación a la idea del ciudadano del mundo, pues no significa el ciudadano de un único pueblo de un Estado único, sino el ciudadano de un pueblo que mantiene su identidad y que está en relación universal con el resto de los pueblos del mundo y sus ciudadanos. En Paz Perpetua el derecho a la ciudadanía mundial es un derecho de hospitalidad, esto es, "el derecho de un extranjero a no recibir un trato hostil por el mero hecho de ser llegado al territorio de otro" (ZeF, VIII: 358, [259]). En Doctrina del Derecho el derecho cosmopolita (Weltbürgerrecht) complementa al derecho político y al derecho internacional para establecer el derecho público. El derecho cosmopolita consiste en "una relación universal de uno con todos los demás, que consiste en prestarse a un comercio mutuo, y tienen el derecho de intentarlo, sin que por eso el extranjero este autorizado a tratarlos como a enemigos" (MS, VI: 352, [192]).

7 En Paz Perpetua Kant agrega que un Estado no puede injertarse en otro Estado porque eso sería "como anular su existencia de persona moral y hacer de esta persona una cosa" (ZeF, VIII: 344, [247]).

8 Cf. J. DiCenso, Kant's Religion within the Boundaries of Mere Reason: A Commentary, op. cit., p. 177.

9 Cf. S. Palmquist, Comprehensive Commentary on Kant's Religion within the Bounds of Bare Reason, United Kingdom, Wiley Blackwell, 2016, pp. 323-324.

10 Como ha señalado O'Neill, Kant describe la iglesia visible como un vehículo, que finalmente será reemplazado cuando una fe más pura y plenamente razonada suplanta a la fe eclesiástica ( Cf. O. O’Neill, Constructing authorities: Reason, politics and interpretation in Kant's philosophy, Cambridge, Cambridge University Press, 2015, p. 246).

11 Frente al argumento de que los Estados deben salir del estado de naturaleza en el que se hallan entre sí para alcanzar un estado de seguridad y de fin a las guerras, podemos hallar la postura de Flikschuh, según la 
cual el derecho internacional tiene como fin, más que la seguridad, una transformación gradual y constante del derecho provisional en perentorio ( $C f$. K. Flikschuh, Kant and modern political philosophy, Cambridge, Cambridge University Press, 2000, p. 176).

12 Aquí me diferencio de: S. Byrd / J. Hruschka, Kant's Doctrine of Right. A Commentary, op. cit., p. 199; J. DiCenso, Kant's Religion within the Boundaries of Mere Reason: A Commentary, op. cit., p. 177.

13 Como ha señalado Williams, el derecho internacional en Kant tiene como cuestión principal resolver "la integridad soberana absolutamente inviolable de los Estados-nación". Las relaciones internacionales deben basarse en el reconocimiento mutuo de la independencia. (Cf. H. Williams, "Kantian Cosmopolitan Right", Politics and Ethics Review, 3(1), 2007, p. 62). Sobre el concepto de soberanía, Flikschuh hace notar un dilema conceptual: mientras el concepto del derecho para Kant es intrínsecamente coercitivo, y entonces los Estados deberían someterse a una autoridad jurídica supraestatal a nivel internacional, sin embargo, los Estados son ellos mismos supremos ejecutores del Derecho y por ello no pueden ser jurídicamente coaccionados ( $C f$. K. Flikschuh, “Kant's sovereignty dilemma: A contemporary analysis", Journal of Political Philosophy, 18, 2010, p. 471). Flikschuh plantea que el dilema se disuelve si los Estados entran voluntariamente a una Federación coercitiva, dado que así no comprometen su soberanía ( $C f$. K. Flikschuh, "Kant's sovereignty dilemma: A contemporary analysis", Journal of Political Philosophy, op. cit., p. 480). En oposición a ello, a lo largo de este trabajo intento sostener, a partir de una desanalogía estatal, que la condición legal entre los Estados es una Federación voluntaria no coercitiva, solo bajo la cual puede lograrse una condición legal que abarque a todos los Estados respetando el derecho de gentes y el derecho cosmopolita.

14 Entre los intérpretes que sostienen que la concepción resultante de derecho político internacional es la Federación de Estados, la cual proporciona la base de la gobernanza global sin recurrir a una autoridad coercitiva supraestatal, podemos mencionar a: M. Marey, El derecho en Kant: Una investigación de sus fundamentos [en línea], Universidad Nacional de La Plata, Facultad de Humanidades y Ciencias de la Educación, 2010, pp. 276, 287-288.; S. Anderson-Gold, "Cosmopolitan Right: State and System in Kant's Political Theory", in Baiasu S., Pihlström S. and Williams H. (Eds.), Politics and Metaphysics in Kant, Cardif, University of Wales Press, 2011, p. 237); O. O’Neill, Constructing authorities: Reason, politics and interpretation in Kant's philosophy, op. cit., pp. 205-206.

15 Tal como sostienen: P. Kleingeld, “Approaching Perpetual Peace: Kant's Defence of a League of States and his Ideal of a World Federation", European Journal of Philosophy, 12(3), 2004, p. 314; P. Kleingeld, "Kant's changing cosmopolitanism”, op. cit., p. 182; H. Williams, "Kantian Cosmopolitan Right”, op. cit., p. 62; K. Flikschuh, "Kant's sovereignty dilemma: A contemporary analysis", op. cit., p. 484; G. Cavallar, Kant and the Theory and Practice of International Right, op. cit., p. 141. Estos autores plantean que Kant sostiene para el derecho internacional el modelo de una república mundial, pero que alcanzarla no es posible de forma inmediata y directa, sino mediante un camino gradual e indirecto, que consta de dos pasos. El primero consiste en la conformación de una Federación libre de Estados, lo cual permitirá establecer cada vez más un consenso sobre principios normativos para saldar las diferencias culturales, religiosas y del derecho internacional, hasta alcanzar evolutivamente y de forma voluntaria, en un segundo paso, una Federación de Estados con poderes coercitivos, que auspiciaría de garante para el logro de la paz definitiva.

16 Cf. M. Marey, El derecho en Kant: Una investigación de sus fundamentos, op. cit., p. 293.

17 Aquí sigo la interpretación de Wood para quien el mal radical es un mal social ( $C f$. A.Wood, Kant's Ethical thought, Cambridge University Press, Cambridge, 1999, pp. 286-289). He defendido en otro lugar que la teoría del mal radical contiene dos niveles de análisis, uno basado en la Primera Parte de Religión, donde Kant expone el mal en la naturaleza humana y el otro en la Tercera Parte, donde Kant expone el mal en la sociabilidad ( $C f$. N. Quiroga, "El origen, objetivo y función de la comunidad ética en La religión dentro de los límites de la mera razón de Kant”, Anales del Seminario de Historia de la Filosofía, 37(3), 2020, pp. 440-442).

18 Contra la interpretación de que los seres humanos son egoístas por naturaleza, Kleingeld sostiene que "los agentes que actúan por amor propio hacen lo que están inclinados a hacer, su principio es seguir sus propias inclinaciones. Su acción no tiene valor moral. Pero la adopción de este principio no significa que sus acciones sean necesariamente egoístas en el sentido habitual" ( $C f$. P. Kleingeld, Kant and cosmopolitanism: The Philosophical Ideal of World Citizenship, Cambridge, Cambridge University Press, 2012, p. 166). Sin embargo, las acciones por amor propio sí tienen valor moral. La interpretación de Kleingeld no toma en cuenta la formulación del mal radical en la naturaleza humana que Kant da en Religión, en la cual considera que el mal radica en una propensión natural, pero libre, que poseen todos los seres humanos, a invertir el orden de los incentivos al 
incorporarlos en la máxima de acción, de forma que en vez de hacer del incentivo de la ley moral la condición suprema, en cambio, se prioriza los del amor propio y las inclinaciones por sobre el incentivo moral (Cf. RGV, VI: 29, [47]; 36, [56]).

19 Como señala Beade, el caso del "enemigo injusto" representa la única excepción que posibilita la coacción para el ingreso a una condición jurídica internacional (MS, VI: 349, [189-190]), pues la libertad de los otros Estados resulta amenazada por la sola proximidad de un Estado despótico, cuyas acciones resultan contrarias a la paz. Para un tratamiento de dicha excepción $C f$. I. Beade, "Acerca de la relación entre derecho político, derecho de gentes y derecho cosmopolita en la filosofía kantiana del derecho", Las Torres de Lucca. Revista Internacional de Filosofía Política, Vol.7, №13, 2018, pp. 89-92, 99-100).

20 Para una lectura del paralelismo entre la Federación de Estados y la comunidad ética pueden consultarse las propuestas opuestas de: Rossi, para quien el paralelismo representa las diferentes soluciones de Kant para superar el mal social expresado en forma de guerra, interna y externa ( $C f$. P. Rossi, The social Authority of Reason: Kant's critique, Radical Evil, and the Destiny of Humankind, Albany, State University of New York Press, 2005, pp. 77-82); Papish, para quien el paralelismo sirve para mostrar que la guerra no tiene como motivo el mal producto de la naturaleza humana en la forma de agresión y competencia. Tanto la Federación de Estados como la comunidad ética no tienen como fin la superación de dicho mal, sino la superación de "malentendidos mutuos" en opiniones políticas, por un lado, y con respecto a la expresión de la virtud, por el otro (Cf. L. Papish, Kant on evil, Self-Deception, and Moral Reform, New York, Oxford University Press, 2018, pp. 207-220).

21 Kant sostiene que los deberes éticos para las libertades internas no pueden ser coaccionados, la virtud tiene que ser libre (RGV, VI: 99, [124]; MS, VI: 381, [231]). De ahí que no puede sostenerse una interpretación como la de Williams, según la cual "podemos estar obligados a obedecer la ley tanto internamente (a través de la moralidad y la convicción) como externamente a través de esta posibilidad de coerción" (Cf. H. Williams, "Kantian Cosmopolitan Right", op. cit., p. 60).

22 Cf. P. Kleingeld, "Approaching Perpetual Peace: Kant's Defence of a League of States and his Ideal of a World Federation", op. cit., p. 318.

23 Flikschuh dice que "la filosofía moral madura de Kant contiene dos tipos complementarios de orden moral. El reino de los fines de Fundamentación de la Metafísica de las Costumbres representa un orden ético invisible regido por el principio de autonomía como ley relevante de la libertad interna. La condición civil, regida por el principio de legislación externa coercitiva moralmente justificada, representa un orden jurídico" (Cf. K. Flikschuh, "Kant's sovereignty dilemma: A contemporary analysis", op. cit., pp. 474-475). Sin embargo, creo que el problema de esta lectura radica en que basa su interpretación del orden ético únicamente en el reino de los fines que Kant ofrece en Fundamentación y no tiene en cuenta el planteo de Religión sobre la comunidad ética.

24 Flikschuh ha señalado que para Kant no hay dilema entre el cosmopolitismo y la soberanía estatal. Con esto su teoría se aleja de los cosmopolitas actuales que oponen de manera excluyente la justicia internacional (estatista) y la justicia cosmopolita (individualista), pues consideran que la soberanía estatal es un obstáculo para una justicia cosmopolita concebida como la demanda de relaciones justas entre personas individuales a nivel mundial. Por el contrario, lo que Kant llama derecho cosmopolita solo es posible a través de la moralidad de los Estados soberanos (Cf. K. Flikschuh, “Kant's sovereignty dilemma: A contemporary analysis”, op. cit., pp. 469-470.) En esta misma dirección Marey señala, en relación con el derecho cosmopolita y la protección de la soberanía de cada Estado, que "si una ley de los pueblos y un derecho cosmopolita son necesarios, lo son en la medida en que son condiciones de posibilidad para la protección de la legislación autónoma de las voluntades generales de los pueblos. Si limitan las formas en que los Estados pueden comportarse en sus interacciones, es para promover condiciones justas para la auto-legislación autónoma de las diferentes comunidades políticas, no para limitar y poner en peligro su soberanía" (Cf. M. Marey, "Kant's popular sovereignty and cosmopolitanism", Constellations. An International Journal of Critical and Democratic Theory, 2020, p. 368).

25 Anderson-Gold sostiene que todos los Estados deben aceptar el hecho (moral) de que los individuos conservan un derecho original de asociación continua que no se deriva de sus identidades cívicas, sino de la posesión común del suelo. Si se derivaran de sus identidades cívicas, los estados podrían negar a las personas el derecho a salir de sus comunidades. Si este fuera el caso, entonces no solo no podría haber derecho a viajar, sino que los estados en efecto "poseerían" a sus ciudadanos como si fueran "cosas", lo cual Kant afirma que es imposible (Cf. S. Anderson-Gold, "Cosmopolitan Right: State and System in Kant's Political Theory", op. cit., pp. 238-239). Por su parte, Kleingeld sostiene que no solo la idea de la posesión común de la tierra sino también el derecho innato a la libertad proporcionan la base para el derecho cosmopolita. Pues, con ambos principios se 
pueden derivar los tres aspectos centrales del principio de hospitalidad: que los estados y los individuos tienen derecho a intentar visitar otro lugar, que los visitantes potenciales no tienen derecho a inmiscuirse en la esfera de libertad de los demás contra su voluntad, y que ni los estados ni los individuos tienen derecho a rechazar posibles visitantes cuando esto lleve a la aniquilación de su libertad (su desaparición) ( $C f$. P. Kleingeld, Kant and cosmopolitanism: The Philosophical Ideal of World Citizenship, op. cit., 2012, pp. 84-85).

Kleingeld nota que el término Verkehr refiere a todo tipo de interacción y no solo a los intercambios comerciales. Refiere a viajes, migración, intercambio intelectual e incluso a la interacción social y al intento de establecer una comunidad. Por tanto, el derecho cosmopolita abarca una categoría mucho más amplia que los intercambios relacionados con el comercio (Cf. P. Kleingeld, Kant and cosmopolitanism: The Philosophical Ideal of World Citizenship, op. cit., pp. 75-76).

27 Cf. O. O’Neill, Constructing authorities: Reason, politics and interpretation in Kant's philosophy, op. cit., p. 207.

28 En Paz Perpetua Kant expresa una fuerte crítica al colonialismo, pues considera injustos a los estados civilizados que cuando van a tierras extrañas confunden "visitar" con "conquistar" y someten a los pueblos como prisioneros. Es para evitar la conquista colonial que se hace necesario un derecho cosmopolita que complemente el derecho político y de gentes para favorecer a la paz perpetua (Cf. ZeF, VIII: 358-360, [260-261]).

29 Cf. S. Anderson-Gold, "Cosmopolitan Right: State and System in Kant's Political Theory”, op. cit., p. 240.

30 Para un análisis de la concepción del bien supremo en Religión como un bien social, terrenal y religioso $C f$. N. Quiroga, "El origen, objetivo y función de la comunidad ética en La religión dentro de los límites de la mera razón de Kant”, op. cit., pp. 443-445). 